\title{
Research on Collaborative Development of Cross-Strait Higher Vocational Education of Finance Majors
}

\author{
Shiqi Liu, Jie Fang, Yushui Li \\ Finance school of Fujian Jiangxia University; Internet Financial Co- \\ Innovation Center across the TaiWan-Strait, Fuzhou, 350108, China
}

\begin{abstract}
Under the circumstances of good financial cooperation across the strait, this paper analyses the higher vocational financial education, discussing the prevailing problems as well as finding out the solutions. This paper holds the idea that only mutual benefits and collaborative development can help to develop cross-strait vocational education communication and improve the economic cooperation across the strait, offering competent vocational talents. In this process, such factors as ideal changes, communication and cooperation between schools and enterprises, moreover, mutual cultivation are needed.
\end{abstract}

Keywords: cross-strait financial cooperation; education communication; cooperation between school and enterprise; Mutual cultivation

\section{Introduction}

With the further deepening of cross-strait exchanges, the "Cross-Strait Financial Cooperation Agreement" after the signing of cross-strait financial policy and financial environment for the understanding of the needs of financial professionals at all levels will further improve the talent preparation slightly behind, Financial personnel training up and down a greater effort for cross-strait financial deepening cooperation to provide better talent reserves and personnel support! 
From the realistic situation, as the forefront of cross-strait exchanges, vocational colleges in Fujian Province after a new round of higher education, the number of higher vocational colleges become scarce. After the merger of higher vocational colleges to set up new undergraduate institutions, according to the requirements of running a college, vocational and long-term professional can not continue to survive. In addition, Fujian Province, despite the advantages of Taiwan, but also offer such as "cooperation between Fujian and Taiwan" and other forms of teaching, but professionals in the vocational aspects of the lack of a similar way of training. From the situation in Taiwan, in the case of insufficient students on the island, relying on the island colleges and universities, vocational institutions to fully meet the needs of financial training vocational talent is becoming more and more unrealistic.

Higher vocational talents as an application-oriented, operational talent, for the financial institutions in terms of irreplaceable advantages, although domestic banks and other financial institutions to recruit the current undergraduate degree, or even a master's degree-based, but the largest highly educated talent Short board is unable to immediately adapt to financial jobs. Therefore, in the training of cross-strait financial talents, the future direction of development should be both undergraduate and higher vocational talent training, so as to meet the crossstrait financial institutions a large number of practical needs and long-term development planning.

\section{The related research progress}

In the profession of cross-strait communication, Yao Cai Li (2013) focuses on the financial professional education, specifically to the cross-strait financial professional curriculum, students' employment orientation and professional improvement direction. As the selected example is the Xiamen Marine Vocational and Technical College, which to some extent affected the representation of the study. Wu Xiaolei (2010) from the perspective of accounting disciplines to carry out research, other scholars also include the analysis of tourism management, police professional, professional development, curriculum, teacher training, vocational certificates, scholars are for the professional characteristics of the proposed my own opinion.

After comparing the evaluation system of academic achievement between the two sides of Taiwan, Wang Qin, Li Yuhong and Liu Jianguo (2013) pointed out that the evaluation of higher vocational students should be improved in four aspects: employment orientation, process evaluation, self-evaluation and ability evaluation. Zhang Mingzhou (2012) also pointed out that Taiwan is more to consider the career planning of vocational students, more discussion, including mainland China's curriculum system than the Taiwan region, the Taiwan region more emphasis on academic courses and elective courses, and the mainland While the learning-based curriculum is the main area. Xu Guifu (2015) introduced the principle of setting up higher vocational education in Taiwan is to serve economic construction, set up and adjust the "total control" professional, 
the mainland is mainly dependent on the adjustment of laws and regulations, and all have a certain autonomy, although the central government There is a clear professional directory, but each place has a certain free space. From the research point of view, in general, scholars have taken into account the professional settings, teacher training, social needs and other factors. To this end, the scholars put forward some targeted countermeasures. In the course of communication, we should give play to their strengths and advantages, highlighting the characteristics (Huang Yefeng, 2011); Students should innovate the pre-vocational training model for financial professionals (Chen Yang, 2014); and a feasible suggestion for teachers is virtual education Alliance (Chen Jianwu, 2013; Zhengruo Ling, 2013). It should be pointed out that the above research is mainly aimed at the overall study of cross-strait vocational education and the analysis of specific financial professionals is not much, obviously lagging behind the macroenvironment of cross-strait financial cooperation.

At the same time, it should be noted that the comprehensive study of all aspects, most scholars do not take into account the cross-strait society to treat the differences in attitude of vocational graduates and cross-strait enterprises on the graduates of vocational colleges, undergraduate subjective evaluation of the difference. It should be noted that, up to now, the training of vocational students in the mainland is not undergraduates, and in the social evaluation, work options, vocational students and undergraduate students can not be compared. In this social environment, financial professional vocational students should receive more attention.

\section{The problem analysis in the cross - strait financial vocational students training process}

\subsection{The student evaluation system function and goal of mainland are one- sided and it can not fully reflect the requirements of modern education.}

At present, the evaluation system for students in mainland China mainly includes academic achievement evaluation and employability evaluation, among which the evaluation of students' ability plays an important role, which is embodied in competency standard. Although the parties involved in the evaluation are mainly business, education and professional analysts, but specific to the vocational colleges, subject to human, material and related social resource constraints, the school does not have the business and career analysis into the right Students are specifically evaluated for the possibility.

3.2 The highly educated tendencies in mainland have affected the enthusiasm of mainland universities to participate in cross-strait financial higher vocational education exchanges

Higher vocational education in the mainland has a clear boundary between undergraduate and postgraduate education. Higher vocational students can not 
enter the higher level of undergraduate and postgraduate education through the efforts. This is not conducive to cultivating the enthusiasm of vocational students, but also restricts the ability. In the academic system, the highest vocational college graduates can only reach the level of college, Students can enter the undergraduate course through the undergraduate examination, but the proportion of not more than $5 \%$, which caused the knowledge of vocational students can not be expanded, the ability system subject to certain restrictions.

In contrast, the system of higher vocational education in Taiwan, smooth access to higher education, not only the level of vocational, vocational and postgraduate vocational education is also more complete, which to a large extent can help students make more choices, But also conducive to the cultivation of a more capable system of higher vocational students.

\subsection{The mainland's recognition degree is not high in Taiwan and it can not achieve academic mutual recognition.}

Learning achievement is good, the overall quality is high, the training potential of students is given priority to enter university education, rather than vocational education. At the same time, universities get funding, funding support significantly higher than vocational colleges, while teaching capacity, higher than the requirements of higher vocational education and more stringent. These factors make the mainland's higher vocational education and vocational investment significantly behind the undergraduate, leading to the comprehensive ability of vocational graduates can not be compared with the Taiwan region.

Financial graduates in the mainland can meet the daily work needs of financial institutions, but also adapt to many business skills requirements, but in the highend financial innovation and higher levels of financial comprehensive utilization of the lack of knowledge reserves, can not fully adapt to the ever-changing financial Situation and financial innovation. And these are precisely the advantages of higher vocational education in Taiwan.

\section{The policy recommendations for cross - strait financial higher vocational education coordinated development}

The mainland should establish a meritocracy is to promote the concept, to avoid highly educated tendencies. Mainland China's economic development is fast, but the level of development is not high, structural contradictions. In the training of personnel, pay more attention to academic education, through the expansion of higher education in the form of a large number of people to enter the university study, effectively raising the academic indicators, universal access to higher education. But it should be noted that the current number of college graduates, the employment level and the concept of employment have a certain bias, some basic, physical work demanding nobody cares, and administrative, office and other job opportunities are relatively limited. In addition, with the new generation of farmers gradually out of agricultural production, less engaged in traditional 
manual labour, the direct result is college graduates can not be compared with the manual workers. Therefore, it should be recognized that a healthy socio-economy should consist of talented people at all levels, not just those who are highly educated, and that most people should be given the right jobs and development opportunities.

Financial industry not only need highly educated financial undergraduates, graduate students, but also need hands-on ability, business operations skilled vocational graduates. Higher vocational financial graduates, although in the knowledge level can not be compared with undergraduates, but the business development ability, and customer communication ability has an advantage.

Financial institutions on both sides of the Strait should take advantage of the opportunity of the free trade area and the construction of financial experimental zones in the mainland, and vigorously train and train financial vocational students and cross-strait higher vocational colleges to jointly train financial vocational students across the Taiwan Strait. This provides good conditions for the training of cross-strait financial professionals, and financial institutions will also have greater demand for financial professionals who are familiar with cross-strait financial business and laws and regulations. Therefore, the use of cross-strait financial institutions in the financial experimental area focused on the establishment of institutions, cross-strait colleges and universities to strengthen links between financial enterprises to provide an ideal platform.

The two sides of the strait should play their respective strengths, and form a mode of cultivation and communication in line with their own characteristics. Advantages and characteristics of the mainland There are many institutions of higher learning and vocational colleges, basic research ability, cutting-edge technology and more vocational students a wide range of employment, the market is huge, but vocational students and social evaluation and employability can not and Undergraduate students in the same breath. This is conducive to the two sides launched mutually beneficial cooperation in the cultivation of vocational students to play their respective advantages, the formation of coordinated development. Specifically, the Taiwan region can use the advantages of teachers, training models and mature vocational training system, from the mainland to expand the recruitment of vocational students to cultivate the application of innovation ability of the mainland vocational students, the ability to improve the system, so that both can overcome the shortage of students on the island of Taiwan, the relative excess of teacher difficulties, but also use the advantages of Taiwan's financial resources for the mainland vocational students to provide better, higher levels of vocational education services. At the same time, mainland China also recruited excellent financial students in Taiwan, using the mainland's research system and academic education, to enhance Taiwan's education level.

\section{Conclusion}

From the perspective of the major policies of the state, cross-strait economic and trade exchanges have deepened, and exchange between the two sides of the strait 
has been more and more frequent, from primary education to higher education, and from academic education to vocational education. In particular, the signing of the Financial Cooperation Agreement between the two sides of the Straits in 2009, the financial exchanges and cooperation between the two sides of the Taiwan Straits has deepen, and the development of cross-strait financial markets will be more stable and cross-strait economic and trade exchanges will be more convenient. Compared with financial higher education, financial higher vocational education has the traits such as low threshold, practicality, short academic system and quick effect, and it paled an important role in meeting the needs of cross-strait economic and trade development. Therefore, we need to further study and discuss the development of cross-strait financial professional vocational education, especially the coordinated development of higher vocational education to better meet the growing cross-strait economic and trade needs.

\section{Acknowledgements}

The second batch of Class A Humanities and Social Sciences Research Project (Cross-Strait Vocational Education Special Project) in 2014, Fujian Province Middle-Aged and Young Teachers Education and Scientific Research Project. Approval number: JAS14573, "The cross-strait financial higher vocational education coordinated development research - taking Fujian and Taiwan financial higher vocational education cooperation as the focus"

\section{References}

[1] Yan Yukang. Comparative study of higher vocational education across the Taiwan Straits, The Scientific Age 55(12), pp.68-70, 2011

[2] Wu Guiming. Chinese Higher Vocational Education Reform under the View of "Human-oriented" Value. Journal of Fujian Institute of Public Administration, 8 (5), pp.87- 91, 2013

[3] Zheng Wenqian. The Comparison and Development of Higher Vocational Education Cooperation between Fujian and Taiwan. Heilongjiang Higher Education Research, 12(10), pp. 18- 20, 2012

[4] Yang Jingzhong. Comparison and Reference of Fiscal and Tax Policies Supporting Cross-Strait Education Development. Journal of Jiangnan University: Humanities and Social Sciences, 9(6), pp.58- 61, 2011

[5] Wu Xiaolei. Study on Curriculum System of Accounting Specialty in Higher Vocational Education: Reference from Taiwan Vocational Education. China Higher Education Research, 8(4), pp.85-87, 2014 